\title{
The role of organizational culture for creating understanding and trust through internal crisis communication
}

\author{
Dr. Albena Björck \\ Zurich University of Applied Sciences \\ Winterthur, Switzerland \\ Prof. Dr. Petra Barthelmess \\ Zurich University of Applied Sciences \\ Winterthur, Switzerland
}

\begin{abstract}
Understanding and trust are major goals of the internal communication in general. In a crisis situation with its inherent uncertainty and lack of time their importance is elevated to a new level. The crisis communication theory lacks a cultural contextualization and a long-standing tradition for including the influence of organizational culture. The purpose of this study is to enhance the understanding of corporate culture as a key factor for internal crisis communication and its effectiveness. It investigates how the visible and less visible levels of culture manifest themselves in the internal crisis communication practice and identifies organizational culture patterns that support or impede understanding and trust.
\end{abstract}

Keywords - internal crisis communication, multinational companies, organizational (corporate) culture, strategic crisis communication

SUGGESTED CITATION: Björck A., \& Barthelmess P. (2020). The role of organizational culture for creating understanding and trust through internal crisis communication. Proceedings of the International Crisis and Risk Communication Conference, Volume 3 (pp. 17-20). Orlando FL: Nicholson School of Communication and Media. https://www.doi.org/10.30658/icrcc.2020.4

\section{INTRODUCTION}

Internal crisis communication takes place inside the organization and thus, it targets the internal stakeholders. Therefore, the impact of organizational culture on crisis communication practice cannot be underestimated. Evidence for the influence of culture demonstrates that despite well-planned and formulated internal communication, a comparison of managers' intentions and employees' interpretations can often show misinterpretation, that creates atmosphere of mistrust and results in resistance.

However, crisis communication theory lacks cultural contextualization. Only few studies analyze the connection between internal crisis communication and organizational culture. This paper aims to foster a better understanding of the organizational culture impact on internal crisis communication and its effectiveness. It offers an outline of the relevant literature and delivers first insights into culturally sensitive internal crisis communication themes. Furthermore, the paper identifies patterns of organizational culture and crisis communication that support understanding and trust.

\section{THEORETICAL FRAMEWORK}

The organizational culture is the accumulated learning by a group and can be defined as a pattern of shared beliefs, values and behavioral norms learned by this group as it solved problems over time [1]. On the one side, through constant interactions with others, people continuously shape and re-shape culture. On the other side culture creates stability and rigidity in an organization imposing to employees how they should perceive, feel and act in a given situation [1]. Organizational culture can be analyzed on different levels, or degree of visibility to the observer [1] and by applying the culture dimensions discussed by [2] and [3]. According to [1] on the first level of artefacts are elements of the culture that can be seen, heard or felt. The second level of the espoused beliefs and values is often visible as a general guideline for 
behavior and interpretation stated in the organizational philosophy often articulated in mission and vision statements. The last, and not visible, level are the basic underlying assumptions, which represent an unwritten rule book about what matters, how to react and what actions should be taken in different situations.

[2] and [3] offered another tool to analyze culture: seven [2] respectively six [3] cultural dimensions help identify and organize value preferences so that the resulting patterns can be categorized along cultural divide. The six respectively seven dimensions are pairs of opposing value orientations: universalism versus particularism, individualism versus communitarianism, specific versus diffuse, neutral versus emotional, achievement versus ascription, sequential versus synchronous time, internal versus outer direction. Cultures very often reveal a certain level of coherence when it comes to value orientation, either staying within the first or the second of the six respectively seven cultural dimension pairs.

A strong organizational culture has to be consistent in the different levels: Espoused values are consistent with formal practices, which are consistent with informal beliefs and norms [4]. The less consistency the more misunderstandings and cultural conflicts in the organization [4].

Organizational culture is seen as an integral part of corporate identity and an input factor for communication practices [5]. Shared cultural rituals and routines shape implicit patterns of communication that enable effective exchange of information in the sense of what is told is understood correctly. A shared value and beliefs system generate implicit rules of social interaction that create trust. The level of trust decides about the credibility of the sender's message and whom the information is given to and whether and how much information is given to the receiver. Internal communication delivers information about the culture within the organization. The explicit communication among different hierarchical levels as well as the quantity and the quality of the informal communication and rumors represent and shape the organizational culture [6]. In other words, internal communication is influenced by culture, but culture is also influenced and formed by internal communication.

In a crisis, the internal communication practice is confronted with challenges such as uncertainty, lack of information, conflicting interpretations, time pressure, fear of mistakes, need for constant and recurring communication [7]. Taking into account this specific context [6] argues that communication culture is part of the organizational culture and during a crisis it can manifest itself in the internal crisis communication practice such as communication strategies, statements, form of expression or design. [8] confirm that organizational culture influences the communication and management of a crisis and point out, that when organizations are under pressure, they tend to take decisions based on routines, explicit or implicit.

\section{METHODS}

The analysis of a less known phenomenon such as the organizational culture's influence on internal crisis communication requires in-depth insights within organizations and crisis contextualization. For this purpose, a qualitative methodology was applied. Multiple-case studies based on semi-structured face-to-face interviews were conducted in the offices of seven multinational companies, based in Switzerland. The interviewed company representatives were communication executives (CEO, head of communication). The information from the interviews was triangulated by an analysis of company and crisis situation information and observation of visible culture features. The internal crisis communication was in the context of structural company crises, and not emergency situations. The seven case studies have been compared and thematic and analytic coding were employed.

In this paper a three-step approach for cultural contextualization was followed. First, the manifestation of the different levels of organizational culture in the core themes of internal crisis communication was analyzed. Second, these core themes were filtered through the cultural dimensions and five culturally affected themes were identified. Third, recurrent and most prominent opposing pattern pairs in the five themes of the internal crisis communication (ICC) emerged.

\section{RESULTS}

Three groups of results convey the influence of organizational culture on the internal crisis communication:

1. The internal crisis communication core themes are influenced by the different levels of organizational culture. The first level of artefacts and behavior is visible in the employed communication channels (examples from the cases: faceto-face, e-mail), the direction of communication (examples: cascade top down, at once to all employees) and responsibilities (examples: centralized in a specialized department or top management task). The second level of espoused values influences the objectives and messaging (examples: what to do? emotional messages of care) as well as organizational values implemented in existing plans and guidelines (examples: timing and frequency, coordination). The last, invisible, level of the basic assumptions forms the implicit employee expectations, implicit communication rituals and routines, informal responsibilities during a crisis.

2. After comparing the six cases and filtering through the culture dimensions, recurrent and most prominent opposing pattern pairs in internal crisis communication (ICC) emerged along the following five themes: process and coordination, dispersion and objectives, timing and messaging, routines and rituals, responsibility and channels (see Figure 1). 


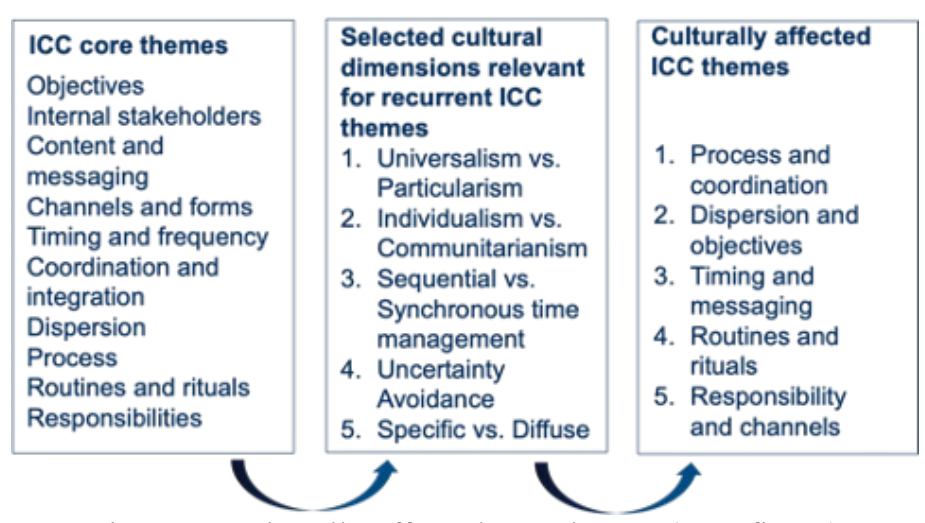

Figure 1: Culturally affected ICC themes (own figure)

3. The cases comparison revealed also core dichotomies in the five culturally affected internal crisis communication themes, that represent two opposite and consistent patterns of organizational culture. The first cultural pattern is built upon regulated and prepared communication (pre-defined guidelines and centralized processes), confidential and selective information provision and reception, focus on avoidance of information leakage, slow reaction due to detailed and accurate situation analysis preceding crisis communication aiming for distributing only correct information, if necessary step by step, mistake avoidance because of shame and zero-error culture, divided responsibility between communication experts and leadership, usage of indirect channels (intranet). The opposite and second cultural pattern represents a flexible and spontaneous communication and missing pre-defined processes, open and transparent provision of information to all with the focus on rumor avoidance, instantaneous information delivery aiming for avoiding anxiety among staff, solution oriented approach with mistake and risk tolerance, encouraging transparency about mistakes, top management responsibility and direct communication channels.

\section{DISSCUSSION}

Organizational culture is fundamental for the internal crisis communication practice. This study enhances this understanding and offers a starting point for further research by combing the organizational culture and internal crisis communication perspectives.

The contributions of this study can be summarized as follows:

First, for the first-time internal crisis communication themes were assigned to the three levels of organizational culture. The existing literature concentrated mainly on statements, strategy, form and design of message. Further elements such as process, timing or responsibility can be also strongly connected to the organizational culture.

Second, based on the assumption that a strong organizational culture is the foundation for an effective internal crisis communication, the study concludes that a congruence between the visible ("Artefacts \& Behavior", "Espoused Values") and deeper, less visible ("Basic Assumptions") levels of organizational culture and corresponding crisis communication themes is needed. Inconsistencies can cause weakening of the culture and result in confusion, misunderstandings, rumors and loss of trust and engagement.

Third, another innovation of this study is the identification of culturally affected internal crisis communication themes pairs by using the culture dimensions and the identification of a dichotomy of culture and communication patterns. Again, keeping in mind the notion of consistency, an effective internal crisis communication is in line with the general organizational culture and stays within the organization's cultural patterns. Ad hoc deviation causes confusion, disorientation and distrust among internal stakeholders.

The results of the study have numerous limitations. Different types of crisis call for different crisis management and communication effort. The interviews focus on structural crises, and not on emergency situations such as environmental disasters or terror attacks. The influence of corporate culture before, during and after the crisis is not investigated. Further research should explore in more detail which parameters of corporate culture can be adjusted as part of the organizational crisis preparedness. A crisis situation always triggers change in the corporate culture. Future research could investigate how internal crisis communication can accompany and intensify the learning from the crisis and mistakes and how it can contribute to a new resilient culture. The insights were won in Swiss companies operating in international context, reflecting Swiss corporate values. The interviews are of limited number, and mainly in the manufacturing industry. The interview partners represent only the management and decision-makers level. Future studies should include also the employees' perspective. Further research could identify how different organizational culture types are reflected in the internal crisis communication practices. Another challenge is the involvement of the differentiation and fragmentation perspectives of organizational culture and their effect on communication effectiveness. Last but not least, the findings are limited to qualitative research approach. 


\section{CONCLUSION}

When a person experiences a crisis situation, the reaction, behavior and communication, are largely dictated by his/her initial cultural "DNA code". The same can be said about organizations: Faced with a crisis as a dangerous situation and existential threat, organizations reveal their true and less visible levels of organizational culture. The culture manifests itself in the visible actions and communication of the members of the organization, but even more in the invisible patterns of behavior, that influence the engagement and conviction as drivers for crisis resolution. A consistency between the visible and invisible cultural levels creates an environment of understanding and trust. In this environment, the internal crisis communication can effectively support the crisis management effort.

Executives need to be more sensitive to the complexity of visible and articulated values and behaviors as well as invisible basic assumptions in the formulation and execution of internal crisis communication. Building a consistent crisis culture takes time and a close cooperation between top management, communication, HR and other professionals is important.

\section{Author Biography}

Dr. Albena Björck, Dr. oec. of the University of St. Gallen (Switzerland), currently working at the Zurich University of Applied Sciences, School of Management and Law, bjoe@zhaw.ch.

Prof. Dr. Petra Barthelmess, Professor of Zurich University of Applied Sciences (Switzerland), currently working at Zurich University of Applied Sciences, School of Management and Law, base@zhaw.ch.

\section{REFERENCES}

[1] Schein, E. H. (2010). Organizational culture and leadership. 4th edition. San Francisco CA: Jossey-Bass.

[2] Trompenaars, F., Hampden-Turner, C. (2012). Riding the Waves of Culture: Understanding Diversity in Global Business. $3^{\text {rd }}$ edition. New York: McGraw-Hill Education.

[3] Hofstede, G., Hofstede, G. J., Minkov, M. (2010). Cultures and Organizations: Software of the Mind. $3^{\text {rd }}$ edition. New York: McGraw-Hill Education.

[4] Wilson A.M. (2001). Understanding organisational culture and implications for corporate marketing. European Journal of Marketing, 35, 353-367. https://doi.org/10.1108/03090560110382066

[5] Cornelissen J. (2004). Corporate Communication: Theory and Practice. Sage Publications.

[6] Richter, N. (2007). Interne Kommunikation im Krisenmanagement. Köln: Josef Eul Verlag GmbH..

[7] Björck A. (2016). Crisis Typologies Revisited: An Interdisciplinary Approach. Central European Business Review, 5, 25-37. https://doi.org/10.18267/j.cebr.156

[8] Frandsen F., Johansen W. (2016). Organizational Crisis Communication: A Multivocal Approach. Sage Publications. 